\section{Eva Martínez-Fernández \\ Roman Alberca \\ Pablo Mir \\ Emilio Franco \\ Enrique Montes \\ Pilar Lozano}

\title{
Cluster headache with aura
}

\begin{abstract}
The objective of our study is to report the frequency and characteristics of cluster headache with aura among the population of patients with cluster headache treated in our outpatient neurology clinic. 254 patients were submitted to semi-structured interviews to identify the presence of symptoms similar to the migraine aura. 5 patients who suffered from a cluster headache with aura filled a diary with the characteristics of the pain attacks and the aura. All the patients with either episodic or chronic cluster headache were studied. The pain attacks were associated with symptoms similar to the migraine aura
\end{abstract}

in five patients (2\%). These disorders were usually ipsilateral to the pain and consisted of paresthesias of the trigeminal territory, clumsiness of the limbs or visual disturbances. Neither paresis nor hypoesthesia could be proved by clinical examination during the attack. We propose to reserve the name of cluster headache with aura to these cases that show similar symptomatology to the migraine aura. These manifestations suggest the participation of the central nervous system in this type of cluster headache.

Key words Cluster headache • Aura • Migraine

\section{Introduction}

Cluster headache $(\mathrm{CH})$ is a clinical entity whose diagnostic criteria are highly specific and sensitive [1]. Sometimes this headache is preceded or accompanied by features similar to the migraine aura [2-4]. We report the frequency and characteristics of cluster headache with aura (CHA) among our series of patients.

\section{Materials and methods}

The diagnosis of episodic and chronic forms of $\mathrm{CH}$ was based on the diagnostic criteria of the International Headache Society (IHS) [1]. 254 patients suffering from $\mathrm{CH}$ derived during the last sixteen years to our out-patient neurology clinic for follow-up were submitted by a neurologist to a semi-structured interview in which they were asked about the presence of taste and olfactory sensations, swallowing disturbances, visual abnormalities, paresthesias in the scalp, face or limbs and weakness or clumsiness in the arms and legs. Additional data captured was the length and time of appearance of this "aura" in relation to the pain. Besides, each patient filled a diary with the frequency, intensity and length of the pain attacks. All the patients could be observed in a cluster cycle and occasionally during the pain attack. Three patients were examined during the "aura".

Paraclinical studies included conventional blood tests, cranial magnetic resonance imaging (MRI), computed tomography (CT) and electrophysiological studies, such as the blink reflex and somesthesic evoked responses.

\section{Results}

Of the 254 patients with $\mathrm{CH}, 5$ male subjects (2\%) felt scotomata, paresthesias or clumsiness on the limbs preceding or accompanying the pain attack. No one of these 5 patients had a history of migraine and just one of them had a positive fam- 
ily history of migraine in first-degree relatives (Table 1). Mean age at onset of the pain attacks was 24 years. They were first examined in the neurology out-patient clinic at the mean age of 27 years and they were followed up between 1 and 16 years. $\mathrm{CH}$ was episodic in all cases; however it turned into secondary chronic in case 4 . All these 5 patients had nausea and/or vomiting during the attack and 4 of them also had phonophobia and photophobia. The quality of the pain was throbbing in two patients, searing in other two and bursting in one. Three among the five patients had just one cluster cycle each year and the mean length of the cluster was 65 days (Table 2).

The visual or sensory aura was ipsilateral to the headache in 3 cases, contralateral in 1 case and bilateral in another (Table 3). These features appeared only after several months or years of typical $\mathrm{CH}$ cycles. However, once they began, they tended to persist in the following cycles. The aura appeared before the pain in one patient, at the same time in another one and minutes after the founding of the pain in the 3 remaining patients. In 2 cases the aura persisted hours or days after the disappearance of the pain (Table 3 ).

The neurological examination of the patients was normal. No abnormalities were detected in the paraclinical tests.

\section{Case 1}

A 44-year-old man had developed a throbbing left-sided episodic headache beginning at age 27 years. The headache initiated on the left side of the neck and radiated to the orbit,

Table 1 Characteristics of the 5 male patients with cluster headache with aura

\begin{tabular}{lccccc}
\hline Patient & 1 & 2 & 3 & 4 & 5 \\
\hline Age, years & & & & & 21 \\
$\quad$ Headache onset & 27 & 30 & 15 & 21 & 25 \\
$\quad$ First medical exam & 34 & 37 & 23 & 16 & 26 \\
Follow-up, years & 10 & 1 & 11 & No & Yes \\
Family history of migraine & No & No & No & Secondary chronic & Episodic \\
Type of CH & Episodic & Episodic & Episodic &
\end{tabular}

Table 2 Features of the cluster cycles in 5 male patients with cluster headache with aura

\begin{tabular}{lccccc}
\hline Patient & 1 & 2 & 3 & 4 & 5 \\
\hline Cluster length, days & $20-60$ & $30-60$ & $45-150$ & Chronic & $60-90$ \\
Clusters, n/year & 1 & 1 & 2 & N.A. & 1 \\
Attacks, n/day & 1 & 1 & $1-4$ & $60-120$ & $1-2$ \\
Attack length, min & $30-120$ & $30-45$ & 2 & 2 & 3 \\
Intensitya & $1-2$ & 2 & Searing & Throbbing \\
Quality & Throbbing & Searing & & &
\end{tabular}

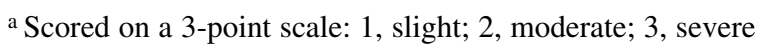

N.A., not applicable

Table 3 Features of the aura in 5 patients with cluster headache with aura

\begin{tabular}{|c|c|c|c|c|c|}
\hline Patient & 1 & 2 & 3 & 4 & 5 \\
\hline Type of aura & Visual, sensory & Sensory & Sensory & Sensory & Sensory \\
\hline Aura length, hours & $0.5-1.0$ & $3-5$ & $1-3$ & Days & 1 \\
\hline Laterality (as regards the pain) & Ipsilateral & Contralateral & Bilateral & Ipsilateral & Ipsilateral \\
\hline Aura before pain & Yes & No & No & No & No \\
\hline Aura accompanying the pain & No & Yes & Yes & Yes & Yes \\
\hline Aura after pain & No & Yes & No & Yes & No \\
\hline Aura out of the cluster cycle & Yes & No & No & No & No \\
\hline
\end{tabular}


where it acquired a throbbing quality. Associated symptoms included ipsilateral nasal congestion and lacrimation. Pain was usually accompanied by nausea, vomiting, phono- and photophobia and was preceded by paresthesias on the left upper and lower limbs and hemianoptic scotomata on the left visual field. He felt tingling in the left foot that spread to the ankle and the external side of the leg and, 15 minutes later, reached the hand, forearm and elbow. He felt tiredness and weakness in both limbs that did not prevent him from walking. The aura appeared 30-60 minutes before the pain and persisted until the beginning of the attack. When the pain attacks appeared at night the patient did not notice this sensory aura. The pain lasted 20 minutes to 2 hours and occurred once a day. Just in rare occasions the pain persisted more than 3 hours. The cluster cycles lasted 1-2 months and appeared once a year, usually in winter time. Fifteen to 20 days before the beginning of the cluster cycle, he noticed paresthesias on the left arm once or twice each day lasting half an hour.

Neurological examination was normal except for the presence of local autonomic signs during the attacks. Neuroimaging and all other studies were normal.

\section{Case 2}

A 38-year-old man, without personal or family history for migraine, developed a stabbing, searing headache behind the right eye irradiating to the ipsilateral temple starting at the age of 30 years. A conjunctival injection and decrease of the lid lag was evident during the pain attacks. Other associated symptoms were phonophobia, photophobia, nausea and vomiting. The patient felt better lying in a dark room and sleeping for a while. However, when it occurred at night, he could not lie still. The pain appeared once a day, usually around 9 a.m., and lasted 30-45 minutes. When the pain reached its intensity peak, he complained of numbness on the left cheek and arm that he compared to the sensation after local anaesthetic injection. This sensation persisted after the attack was over, lasting from 3 to 5 hours. At the beginning, the pain occurred once a year. However in the last two years it appeared once every two months with 2-3 pain-free weeks between the cluster cycles. The neurological examination was normal as was the CT scan.

\section{Case 3}

A 32-year-old man suffered from a periorbital left headache since he was 15 years old. The pain had a bursting and oppressive quality and irradiated to the left nasal wing, cheek and ear. It was accompanied by local autonomic signs (ipsilateral ptosis, conjunctival injection, lacrimation and rhinorrhea), profuse sudoration, photophobia, photophobia and nausea. Previous to the appearance of the pain, he complained of generalized sweating, diarrhea and felt the need to urinate. The pain occurred during nocturnal or diurnal sleep, more frequently around 6-7 a.m., 1-4 times a day. The patient could not lie still when the pain appeared and usually got up and walked from one place to another. The usual length of the pain was one hour and the cluster cycles lasted from 1.5 to 5 months twice a year (usually in spring or summer). When he was 23 years old, he began noticing tingling in both hands and feet that began 45 minutes after the attack onset and persisted until the attack was over. This sensory aura accompanied the attacks from then on.

\section{Case 4}

A 37-year-old man developed a strictly unilateral oppressive, searing headache at age 21 . He described it as "if someone was scratching into his eye". This headache was localized deep into the left eye and irradiated to the maxillary region, reached the intensity peak in 10 minutes, last between 1 and 2 hours and eased off in half an hour. It happened at any time. When it appeared at night, the pain woke him from sleep, but he usually stayed in bed. Associated symptoms were conjunctival injection, lacrimation, miosis, ptosis and nasal congestion. He felt nausea and vomiting but no photophobia or phonophobia. Alcoholic drinks aroused the pain attacks.

The headache had an episodic course, but it became chronic by the age of 22 years.

When he was 32 years old, he began complaining of clumsiness on his left foot that he noticed when he engaged the clutch of the car, and numbness and tingling on the upper and lower left limbs. It appeared at the attack onset, continued throughout the attack and persisted for days after the pain disappearance. The numbness on the limbs disappeared when he moved them and never reached the face. Sometimes he felt clumsiness on the left limbs outside the headache. The neurological examination during the attack did not reveal any abnormalities and a brain CT, MRI, electroencephalography and Doppler sonography were also normal.

At the age of 33 years, he became free of pain for 3 years and then the pain reappeared with the same features but an episodic course with remissions longer than 2 weeks between the cluster cycles. This time, the headache was also accompanied by a sensory disorder on the left limbs that persisted hours after the pain attack.

\section{Case 5}

A 36-year-old man developed a stabbing and throbbing 
excruciating unilateral headache starting at the age of 25 years. His mother and 6-year-old daughter suffered from migraine. The headache was located over the right maxilla and irradiated to the eye, forehead and ear. The peak of intensity was behind the eye and temple. The pain attacks were accompanied by conjunctival injection, lacrimation and rhinorrhea. Nausea, phonophobia and photophobia were also present in most of the attacks. He usually lay in bed during the pain attack. Pain attacks usually happened around midnight, lasted for one hour, once or twice a day for 2-3 months. He had, at least, one cluster cycle each year. He worked as a confectioner and related the cluster cycles to the frequent changes of shift. In fact, the only year he had been free of pain was the one in which he stayed in a fixed shift. When he was 27 years old, during a cluster cycle, he felt numbness and weakness on the right leg and arm that was clear when he tried to make an effort such as holding a heavy object with his hand. He also complained of cramps on his arm. This disorder began 15 minutes after the appearance of the headache and persisted until the attack was over. The neurological examination was normal during the "aura" as were the blink reflex and somesthesic evoked responses. This sensory aura continued accompanying the pain attacks for the following years. In the last six years the frequency of clusters has fallen and now occurs once every two years.

\section{Discussion}

According to the IHS classification [1], $\mathrm{CH}$ and migraine are two different entities. Whereas migraine is more frequent in women and often has a familiar presentation, $\mathrm{CH}$ is usually sporadic and most of the patients are men. Other clinical characteristics that differentiate $\mathrm{CH}$ from migraine include the localization, quality and duration of pain, pres-

Table 4 Cases of cluster headache with aura reported in the literature

\begin{tabular}{|c|c|c|c|c|c|c|c|c|}
\hline \multirow[t]{2}{*}{ Patients } & \multirow[t]{2}{*}{ Sex } & \multicolumn{2}{|c|}{ Migraine } & \multicolumn{2}{|c|}{ Age, years ${ }^{\mathrm{a}}$} & \multirow[t]{2}{*}{ Aura type } & \multicolumn{2}{|c|}{ Length } \\
\hline & & Prev. & Coex. & $\mathrm{CH}$ & Aura & & $\mathrm{CH}$ & Aura \\
\hline \multicolumn{9}{|c|}{ Medina, Diamond [2] } \\
\hline 1 & M & - & - & 24 & 24 & Visual & $30-60 \mathrm{~min}$ & $5 \mathrm{~min}$ \\
\hline 2 & M & - & + & 46 & 46 & Visual & $60 \mathrm{~min}$ & $30-45 \mathrm{~min}$ \\
\hline 3 & M & - & - & 35 & 35 & Visual & $20-120 \mathrm{~min}$ & $20-120 \mathrm{~min}$ \\
\hline 4 & M & - & - & 38 & 38 & Sensory & $20-45 \mathrm{~min}$ & $3 \mathrm{~min}$ \\
\hline 5 & $\mathrm{~F}$ & - & - & 10 & 32 & Sensory, motor & $60-120 \mathrm{~min}$ & $12-24 \mathrm{~h}$ \\
\hline \multicolumn{9}{|c|}{ Guiloff, Fruns [17] } \\
\hline 1 & M & - & - & 9 & 35 & Algesic & NR & NR \\
\hline 2 & M & + & + & 12 & 31 & Sensory, algesic & NR & NR \\
\hline 3 & $\mathrm{~F}$ & - & - & 24 & 24 & Sensory, algesic & NR & NR \\
\hline 4 & M & + & - & 40 & 52 & Motor, algesic & $24 \mathrm{~h}$ & $24 \mathrm{~h}$ \\
\hline 5 & $\mathrm{~F}$ & + & + & 15 & 31 & Algesic & NR & NR \\
\hline 6 & M & - & - & 34 & 38 & Algesic & NR & NR \\
\hline 7 & M & + & - & 11 & 33 & Algesic & NR & NR \\
\hline 8 & $\mathrm{~F}$ & - & + & 33 & 33 & Sensory, algesic & $180 \mathrm{~min}$ & Days \\
\hline 9 & $\mathrm{~F}$ & - & - & 44 & 44 & Algesic & $60-180 \mathrm{~min}$ & $60-180 \min$ \\
\hline 10 & $\mathrm{~F}$ & + & + & 16 & 19 & Sensory, algesic & NR & NR \\
\hline 11 & $\mathrm{~F}$ & + & - & 14 & 16 & Algesic & NR & NR \\
\hline 12 & $\mathrm{~F}$ & - & - & 12 & 12 & Motor, algesic & NR & NR \\
\hline 13 & $\mathrm{~F}$ & - & - & 15 & 59 & Algesic & NR & NR \\
\hline 14 & $\mathrm{~F}$ & + & - & 18 & 17 & Algesic & NR & NR \\
\hline 15 & $\mathrm{~F}$ & + & + & 23 & 37 & Motor, sensory, algesic & NR & NR \\
\hline \multicolumn{9}{|c|}{ Silberstein et al. [3] } \\
\hline 1 & M & - & - & 42 & 42 & Olfactory & $30-60 \mathrm{~min}$ & $30-60 \mathrm{~min}$ \\
\hline 2 & M & - & - & 12 & NR & Visual & $45 \mathrm{~min}$ & $15 \mathrm{~min}$ \\
\hline 3 & $\mathrm{~F}$ & - & - & 12 & 12 & Visual & $60 \mathrm{~min}$ & $45 \mathrm{~min}$ \\
\hline 4 & M & - & - & 22 & NR & Visual & $120 \mathrm{~min}$ & $5 \mathrm{~min}$ \\
\hline 5 & $\mathrm{~F}$ & + & + & 27 & 27 & Visual & $90 \mathrm{~min}$ & $120 \mathrm{~min}$ \\
\hline 6 & M & - & - & 35 & 35 & Visual & $40 \mathrm{~min}$ & $30 \mathrm{~min}$ \\
\hline
\end{tabular}

a Age at the beginning of the symptomatology

$N R$, not reported; $\mathrm{CH}$, cluster hedache; Prev., previous history of migraine; Coex., migraine coexisting with cluster headache 
ence of autonomic signs and clustering of attacks. These clinical differences are undoubtedly related to the different physiopathological mechanisms present in these two disorders. Moreover, during migraine and $\mathrm{CH}$ attacks there is a respective activation of the brain stem and hypothalamus that does not appear in the other type of vascular headache [5]. The only common pathogenic mechanism in both headaches is the trigeminovascular activation, shared by a large number of headaches [6].

Several authors have discussed the coexistence of $\mathrm{CH}$ and migraine in the same patient $[2,4,7,8]$. This association is not frequent. According to Anderson [7], 15\% of patients with $\mathrm{CH}$ had a previous history of migraine, but the persistence of the migraine, once the cluster appeared, was as low as $1.5 \%$. The coexistence of both types of headaches in the same patient seems to happen by chance, since it is rare, and, once the cluster begins, the migraine usually disappears. Nonetheless, it is not possible to discard definitely that there is a common causal factor for both entities, for example, a common genetic predisposition [9].

Solomon used the term cluster-migraine to describe a condition that shows components of cluster headache and migraine [4]. However, the term cluster headache with aura (CHA) [3] is more appropriate to describe the appearance in cluster attacks of symptoms that are considered typical of migraine. Sometimes they are just nausea, vomiting, phonophobia and photophobia [10]. Nevertheless, according to Nappi et al. [11], 55.8\% of patients with $\mathrm{CH}$ feel photophobia, whereas $40.6 \%$ have nausea and $23.9 \%$ vomiting. Therefore, it is not reasonable to establish a subtype of $\mathrm{CH}$ based on these nonspecific features so frequent in typical $\mathrm{CH}$. Moreover, sometimes, the nausea and vomiting are related to the therapy used in this headache, which suggests that $\mathrm{CH}$ should not be classified as a different entity just because of the presence of these symptoms.
Patients suffering from $\mathrm{CH}$ frequently feel hypersensitivity on the scalp or discomfort while swallowing during the pain attacks. Sometimes they feel itching over the eyebrows or the nasalwing ipsilateral to the pain. $\mathrm{CH}$ is related to a disorder of the first branch of the fifth cranial nerve $[5,12]$ and therefore, the aforementioned feelings could reasonably be due to this peripheral trigeminal disorder [13]. On the other hand, some patients with $\mathrm{CH}$ describe unpleasant taste and olfactory sensations at the beginning of the attack. It is difficult to understand whether these symptoms are also related to the trigeminal disorder or whether a phenomenon with a central origin constitutes an "aura" [3].

Finally, some patients have similar symptoms to the migraine aura preceding or accompanying the pain attacks. The frequency varies, depending on the series, between $2 \%$ in our study to $3.1 \%$ in that of Silverstein et al. [3]. Sometimes the symptoms are visual manifestations such as scotomatas, twinkling lights or achromatopsia (Table 4) [2-4,14-16]. Other series reported sensory aura, such as itching, pain or clumsiness [2, 4, 15, 17].

In our series, we describe just one patient with visual aura. All the patients had sensory disturbances. Four of them also complained of weakness on the limbs, but this deficit was not proved by neurological examination, which suggests that it must be a sensory or subjective sensation rather than a real paresis. The persistence of this aura in case 4 is striking. Just one case with an aura lasting so long has been described in the literature [2].

The progression and distribution of the aura in $\mathrm{CH}$, resembling the migraine aura, supports the hypothesis of a central origin and not a trigeminal one.

Acknowledgement This paper is partially supported by grants from FIS (00/0568) and SAS (30/99).

\section{References}

1. - (1988) Classification and diagnostic criteria for headache disorders, cranial neuralgias and facial pain. Headache Classification Committee of the International Headache Society Cephalalgia 8[Suppl 7]:1-96

2. Medina JL, Diamond S (1977) The clinical link between migraine and cluster headaches. Arch Neurol 34:470-472

3. Silberstein SD, Niknam R, Rozen TD, Young WB (2000) Cluster headache with aura. Neurology 54:219-221
4. Solomon S (1986) Variants of cluster headache. In: Vinken PJ, Bruyn GW, Klawans HL, Rose FC (eds) Handbook of clinical neurology: Headache, vol 4 (48). Elsevier Sciences, Amsterdam, pp 267-271

5. Goadsby P, Bahra A, May A (1999) Mechanism of cluster headache. Cephalalgia 19[Suppl 23]:19-23

6. Moskowitz MA (1990) Basic mechanisms in vascular headache. Neurol Clin 8:801-815
7. Andersson PG (1985) Migraine in patients with cluster headache. Cephalalgia 5:11-16

8. D’Amico D, Vincenzo C, Grazzi L, Leone M, Riccheti G, Bussone G (1997) Coexistence of migraine and cluster headache: Report of 10 cases and possible pathogenetic implications. Headache 37:21-25

9. Kudrow L, Kudrow DB (1994) Inheritance of cluster headache and its possible link to migraine. Headache 34:400-407 
10. Wheeler SD (1998) Significance of migraneous features in cluster headache: divalproex responsiveness. Headache 38:547-551

11. Nappi G, Micieli G, Cavallini A, Zanferrari C, Sandrini G, Manzoni GC (1992) Accompanying symptoms of cluster attacks: their relevance to the diagnostic criteria. Cephalalgia 12:165-168
12. Goadsby PJ, Edvinsson L (1994) Human in vivo evidence for trigeminovascular activation in cluster headache. Neuropeptide changes and effects of acute attacks therapies. Brain 117:427-434

13. Alberca R (1997) Variedades inusuales de cefalea en racimos. Neurologia 12[Suppl 5]:38-43

14. Duvoisin RC, Parker GW, Kenoyer WL (1961) The cluster headache. Arch Intern Med 108:711-716
15. Lance JW, Anthony M (1971) Migrainous neuralgia or cluster headache? J Neurol Sci 13:401-414

16. Graham JR (1972) Cluster headache. Headache 11:175-185

17. Guiloff RJ, Fruns M (1988) Limb pain in migraine and cluster headache. $\mathrm{J}$ Neurol Neurosurg Psychiatry 51:1022-1031 